\title{
Author Correction: Incorporation of Ursolic Acid in Liquid Crystalline Systems Improves the Antifungal Activity Against Candida sp.
}

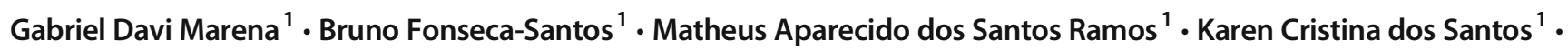
Taís Maria Bauab ${ }^{1}$ - Marlus Chorilli ${ }^{1}$

Published online: 28 August 2020

(C) Springer Science+Business Media, LLC, part of Springer Nature 2020

Author Correction: Journal of Pharmaceutical Innovation https://doi.org/10.1007/s12247-020-09470-0

The original version of this article unfortunately contained a mistake. The name of the 3rd author was incorrectly presented. The correct name of the 3rd author is "Matheus Aparecido dos Santos Ramos."

Publisher's Note Springer Nature remains neutral with regard to jurisdictional claims in published maps and institutional affiliations.

The online version of the original article can be found at https://oi.org/ $10.1007 /$ s12247-020-09470-0

Marlus Chorilli

marlus.chorilli@unesp.br

1 School of Pharmaceutical Sciences, São Paulo State University

(UNESP), Araraquara, São Paulo 14800-903, Brazil 